\title{
Effects of w-3 Fatty Acid Supplementation in Patients with Bile Duct or Pancreatic Cancer Undergoing Chemotherapy
}

\author{
KYOHEI ABE, TADASHI UWAGAWA, KOICHIRO HARUKI, YUKI TAKANO, \\ SHINJI ONDA, TARO SAKAMOTO, TAKESHI GOCHO and KATSUHIKO YANAGA \\ Department of Surgery, The Jikei University School of Medicine, Tokyo, Japan
}

\begin{abstract}
Background/Aim: Omega-3 fatty acids may improve cancer cachexia, but only in patients with pancreatic and bile duct cancer. Patients with pancreatic cancer commonly suffer from exocrine pancreatic insufficiency, and the ingestion of digestive enzyme supplements may improve absorption. Patients and Methods: Racol ${ }^{\circledR}$, an enteral nutrient formulated with omega-3 fatty acids, was administered to patients with unresectable pancreatic and bile duct cancer. The skeletal muscle mass and blood test data were taken pre-administration and at 4 and 8 weeks after. Patients with pancreatic cancer were given the digestive enzyme supplement LipaCreon ${ }^{\circledR}$ from the fifth week after the start of administration. Results: In all 27 patients, skeletal muscle mass was significantly increased at both 4 and 8 weeks after the start of administration versus pre-administration ( $p=0.006, p=0.002$, respectively). Conclusion: Omega-3 fatty acid supplementation in patients with unresectable pancreatic and bile duct cancer may improve cancer cachexia.
\end{abstract}

Blue-skinned fish (pike, mackerel, sardine, etc.) contain rich amounts of omega-3 fatty acids, especially eicosapentaenoic acid (EPA) and docosahexaenoic acid (DHA). Unlike other unsaturated long-chain fatty acids, an omega- 3 fatty acid is structured with a double bond that contains three carbons from the $N$-terminal of the molecule (1). The validity of omega-3 fatty acid supplementation has been reported in various diseases: coronary disease, rheumatoid arthritis, inflammatory diseases, and cancer (2-8). Patients with unresectable cancer that receive routine nutritional support often experience a progressive decline in skeletal muscle mass. Loss of skeletal muscle mass causes cachexia, which

Correspondence to: Kyohei Abe, MD, Department of Surgery, The Jikei University School of Medicine, 3-25-8, Nishi-Shinbashi, Minato-ku, Tokyo 105-8461, Japan. Tel: +81 334331111 ext. 3401, Fax: +81 354724140, e-mail: kyoheiabe@jikei.ac.jp

Key Words: Biliary-pancreatic cancer, omega-3 fatty acids, cancer cachexia. in turn results in the deterioration of physical function (9). Skeletal muscle mass is also directly linked to a patient's activities of daily living and quality of life. Patients with advanced gastrointestinal cancer often require cytotoxic chemotherapy. Many patients with pancreatic and biliary cancer suffer from nutritional instability due to the anatomical and pathological peculiarities of these diseases. According to a recent study, reduced skeletal muscle mass is an indicator of cancer cachexia as well as poor vital prognosis (10).

Omega-3 fatty acids increase the levels of leukotriene and prostaglandin while suppressing the production of inflammatory cytokines [interleukin-6 (IL6), IL8, etc.] $(9,11)$ that potentially cause cancer cachexia (12-14). Wigmore et al. reported weight improvement in weight-losing patients with pancreatic cancer receiving EPA (targeted dose $6 \mathrm{~g} / \mathrm{d}$ ) (15). When Barber et al. supplied 20 weight-losing patients with pancreatic cancer with omega-3 fatty acids (total of $2.2 \mathrm{~g}$ of EPA/day), the patients exhibited stabilized body weights (increase of about $1 \mathrm{~kg}$ ) after 3 weeks of supplementation, along with improvements in appetite and performance status (16).

While several studies have been published on nutritional support for patients with pancreatic cancer $(9,11,15,16)$, we were unable to identify any reports on bile duct cancer in our literature search.

Patients with pancreatic cancer are generally expected to suffer from a disturbance of pancreatic exocrine function. This has prompted speculation that digestive enzyme supplements given in addition to omega-3 fatty acids could further improve the nutritional state of such patients. In the current study, we investigated the usefulness of omega-3 fatty acids as a nutritional support for patients with advanced biliary-pancreatic cancer.

\section{Patients and Methods}

Participants and procedures. The study subjects were patients with unresectable pancreatic and bile duct cancer who underwent chemotherapy between November 2014 and November 2016. Each patient was given $2-4$ packs $(200 \mathrm{kcal} / 300 \mathrm{mg}$ of omega-3 fatty acids per pack) of an omega- 3 fatty acid enteral nutrient (Racol ${ }^{\circledR}$; Otsuka Pharmaceutical Factory, Tokyo, Japan) per day. 


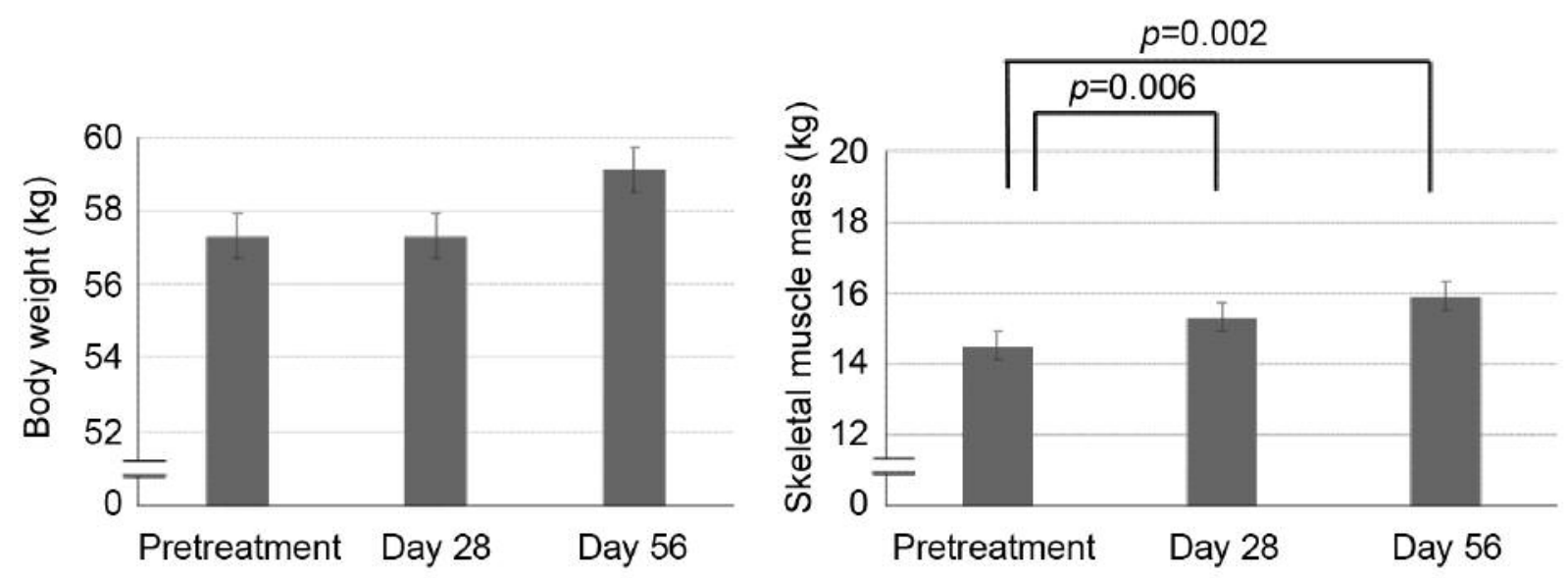

Figure 1. Effects of nutritional support on body weight and skeletal muscle mass in all patients (bile duct and pancreatic cancer patients). Paired t-tests combining data from pre-treatment and week 4, and from pre-treatment and week 8 , were performed for all individual outcome measures of all patients. No significant differences were found in body weight, although a tendency toward improvement was apparent. The skeletal muscle mass values on days 28 and 56 were significantly increased in comparison to pretreatment values.

Outcome measures were assessed pre-treatment and at 4 and 8 weeks after the start of the treatment. Each patient was asked to consume approximately the same number of calories every day (the exact calorie intakes were not calculated). After undergoing pancreatic function diagnostic (PFD) tests (to assess the paraaminobenzoic acid excretion rate and pancreatic exocrine function), patients with pancreatic cancer were additionally given the pancreatic digestive enzyme supplement LipaCreon ${ }^{\circledR}(150 \mathrm{mg}$, 12 times/day; Abbott Japan, Tokyo, Japan) from the fifth week of treatment onwards. This study was approved by the Ethics Committee of the Jikei University School of Medicine (Review number: 260707575). All procedures used were in accordance with the ethical standards of the responsible committee on human experimentation and with the Helsinki Declaration of 1975, as revised in 2008. Informed consent was obtained from all patients prior to inclusion in the study.

Measures. The primary outcome measures were body weight $(\mathrm{kg})$ and skeletal muscle mass $(\mathrm{kg})$. Body weight and skeletal muscle mass were measured by an InBody ${ }^{\circledR}$ weight scale (InBody Japan Inc., Tokyo, Japan). The secondary outcome measures consisted of blood test data [EPA level, EPA/arachidonic acid (AA) ratio, Glasgow prognostic score, rapid turnover protein (RTP), neutrophils, IL6, natural killer (NK) cell activity, hemoglobin A1c (HbA1c), carcinoembryonic antigen (CEA)].

Statistical analysis. Outcome measures were analyzed by comparing the pre-treatment data to the data at the follow-up time points of 4 and 8 weeks after the start of administration; the data were also compared between 4 and 8 weeks. Values are expressed as the mean \pm standard deviation (SD). All evaluation items were compared using paired-sample $t$-tests; $p$-values of less than 0.05 were considered statistically significant. Analyses were conducted using IBM SPSS statistics version 20.0 (IBM Japan, Tokyo, Japan).
Table I. Patients characteristics $(n=27)$.

\begin{tabular}{lcc}
\hline Factor & Mean \pm SD or Ratio & Range \\
\hline Age (years) & $68.8 \pm 4.24$ & $53-81$ \\
Gender (male/female) & $16 / 11$ & \\
Bile duct cancer/pancreatic cancer, n & $8 / 19$ & \\
No. of RACOL ${ }^{\circledR}$ taken (0 to 4 weeks) & $2.37 \pm 0.35$ & $2-4$ \\
No. of RACOL ${ }^{\circledR}$ taken (5 to 8 weeks) & $2.42 \pm 0.7$ & $2-4$ \\
\hline
\end{tabular}

\section{Results}

The sample consisted of 27 patients (16 men and 11 women, mean age $=68.8 \pm 4.24$ years $)$, including 19 with pancreatic cancer and eight with bile duct cancer. The patients ingested an average of $2.4 \pm 0.4$ packs of Racol ${ }^{\circledR}$ per day (Table I). The underlying chemotherapy regimen administered for pancreatic cancer consisted of FOLFIRINOX (levofolinate/fluorouracil/ irinotecan/oxaliplatin) in four patients, gemcitabine plus nabpaclitaxel in two; tegafur/gimeracil/oteracil potassium (TS1) plus gemcitabine in seven, TS 1 in two, GEM in three, and cisplatin plus irinotecan in one. The chemotherapy regimen administered for bile duct cancer consisted of gemcitabine plus cisplatin in seven patients and TS1 in one patient.

Considering that the whole patient cohort demonstrated significant increases in skeletal muscle mass at 4 and 8 weeks post- versus pre-treatment administration ( $p=0.006$ and $p=0.002$, respectively)) (Figure 1). Examinations of other outcome measures revealed improvements in the nutritional 

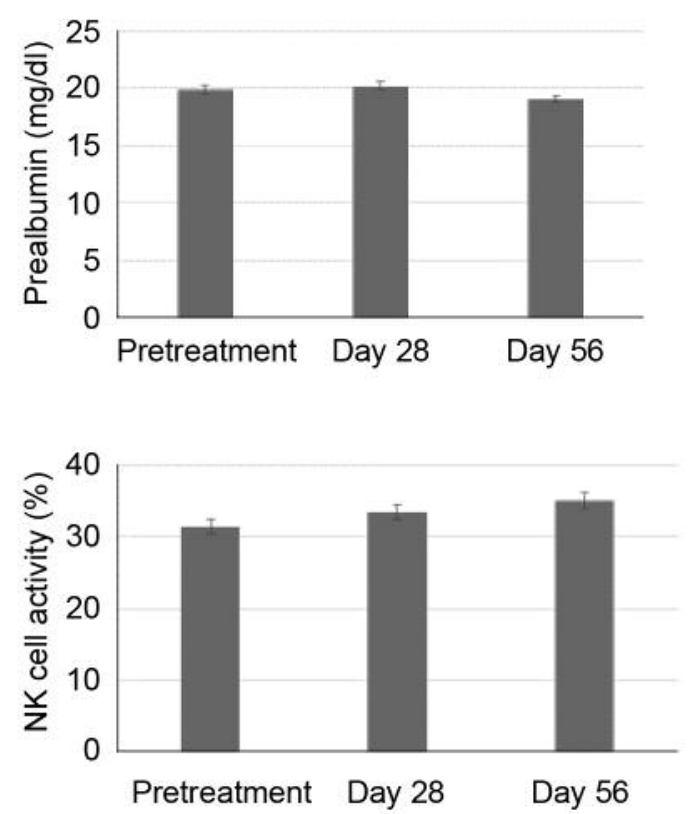
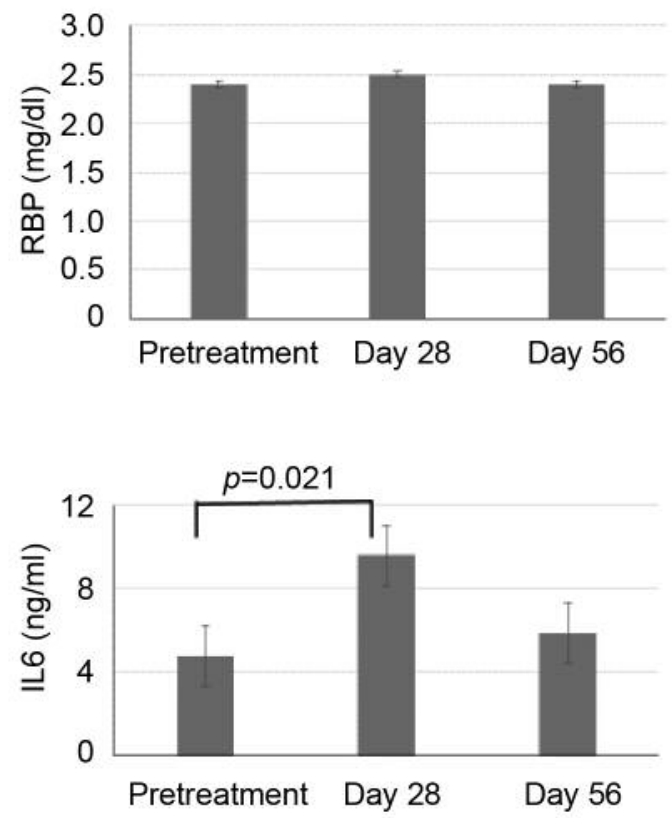

Figure 2. Effects of nutritional support on nutritional and immunological indicators in all patients. For the most part, no significant differences were found in nutritional and immunological indicators in the analysis of all patients.
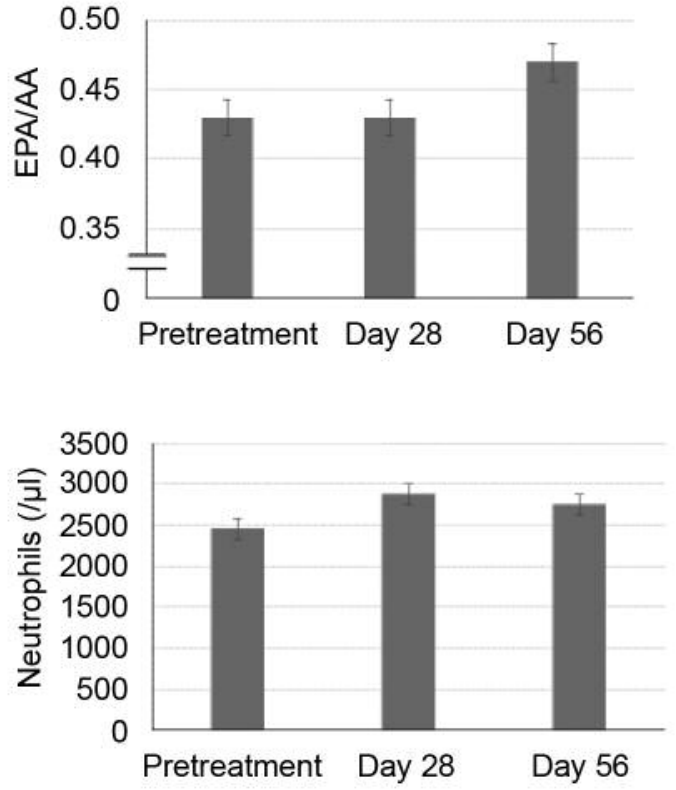
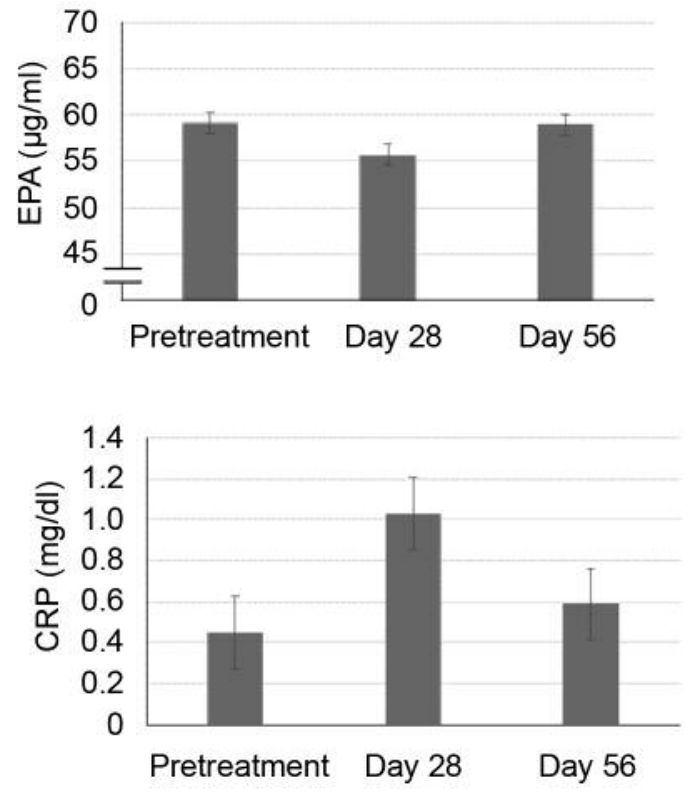

Figure 3. Effects of nutritional support on blood concentrations of eicosapentaenoic acid (EPA) and the levels of neutrophils and C-reactive protein $(C R P)$ in all patients. No significant differences were found in the blood concentrations of EPA or in the levels of neutrophils or CRP in the analysis of all patients.

state and blood EPA levels after treatment, but none of the preto post-differences reached statistical significance (Figures 2-4).

The group of patients with bile duct cancer was rather small and these patients were not given the pancreatic digestive enzyme supplement, therefore, no further analysis of this group was considered.

Among the patients with pancreatic cancer, increases in skeletal muscle mass were observed after 4 and 8 weeks of 

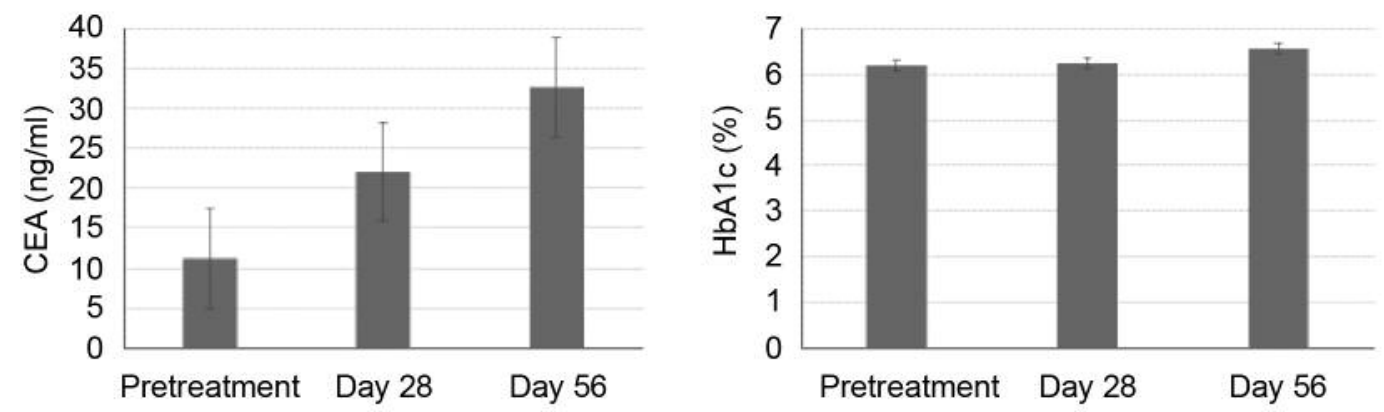

Figure 4. Effects of nutritional support on levels of carcinoembryonic antigen (CEA) and hemoglobin Alc (HbAlc) in all patients. There were no significant increases in CEA or HbAlc in the analysis of all patients.
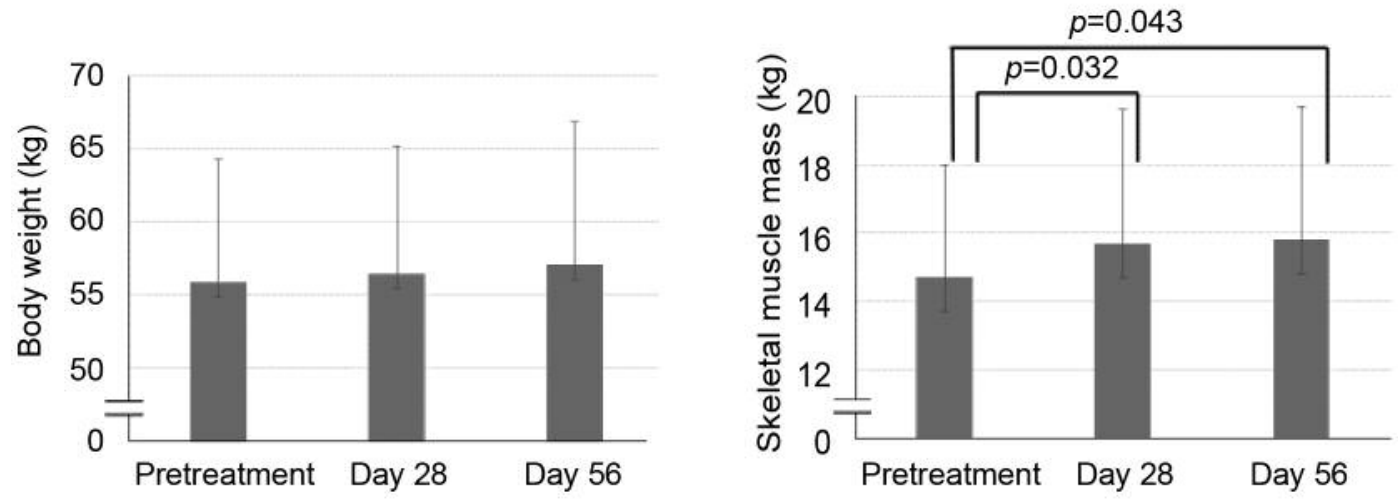

Figure 5. Effects of nutritional support on body weight and skeletal muscle mass in patients with pancreatic cancer. Paired t-tests combining data from pre-treatment and day 28, from pre-treatment and day 56, and from day 28 and day 56 were performed for the individual outcome measures of all of the pancreatic cancer patients. While no significant differences were found in body weight, the skeletal muscle mass was significantly increased at days 28 and 56 versus the pre-treatment level.

treatment compared to the pre-treatment level $(p=0.032$ and $p=0.043$, respectively); however, no significant difference in skeletal muscle mass was observed between weeks 4 and 8. Body weight showed an increasing trend at both 4 and 8 weeks, but the differences versus pre-treatment were not statistically significant (Figure 5). NK cell activity was also significantly increased at week 8 compared to pre-treatment $(p=0.02$; Figure 6). $\mathrm{EPA} / \mathrm{AA}(p=0.044, p=0.018)$ and $\mathrm{EPA}(p=0.011, p=0.021)$ were both higher at week 8 than at pre-treatment or week 4 (Figure 7). While no significant differences were found in the tumor marker CEA, the level showed a clear tendency to increase. HbAlc also increased over time, but not to a statistically significant degree (Figure 8).

\section{Discussion}

Omega-3 fatty acids have been found to mitigate weight loss and improve blood test data in patients with cancer of the lung $(17,18)$, stomach, colon, and rectum (19), pancreas $(11,20$,
21 ), and head and neck (22), presumably by improving the patients' nutritional state and reducing their levels of inflammatory cytokines (9). Omega-3 fatty acids have also been found to markedly reduce the incidence of chemotherapyrelated adverse events in patients with esophageal cancer undergoing chemotherapy (23). Finally, omega-3 fatty acids are reported to improve the therapeutic outcomes of chemotherapy (24). Somewhat less is known, however, about the effects of omega-3 fatty acids on biliary-pancreatic cancer $(11,20,21)$. In the present study, we investigated the effects of pancreatic digestive enzyme supplements added to omega-3 fatty acid nutritional support in patients with pancreatic cancer.

Our pancreatic cancer group exhibited an increase in not only serum EPA level, but also the EPA/AA ratio (a measure of EPA absorption and circulation), at 8 weeks after the start of treatment versus pre-treatment and week 4 levels. While the EPA/AA ratio trended upward at week 4 compared to pre-treatment, the increase at 8 weeks was significantly higher compared with both the pre-treatment and week 4 

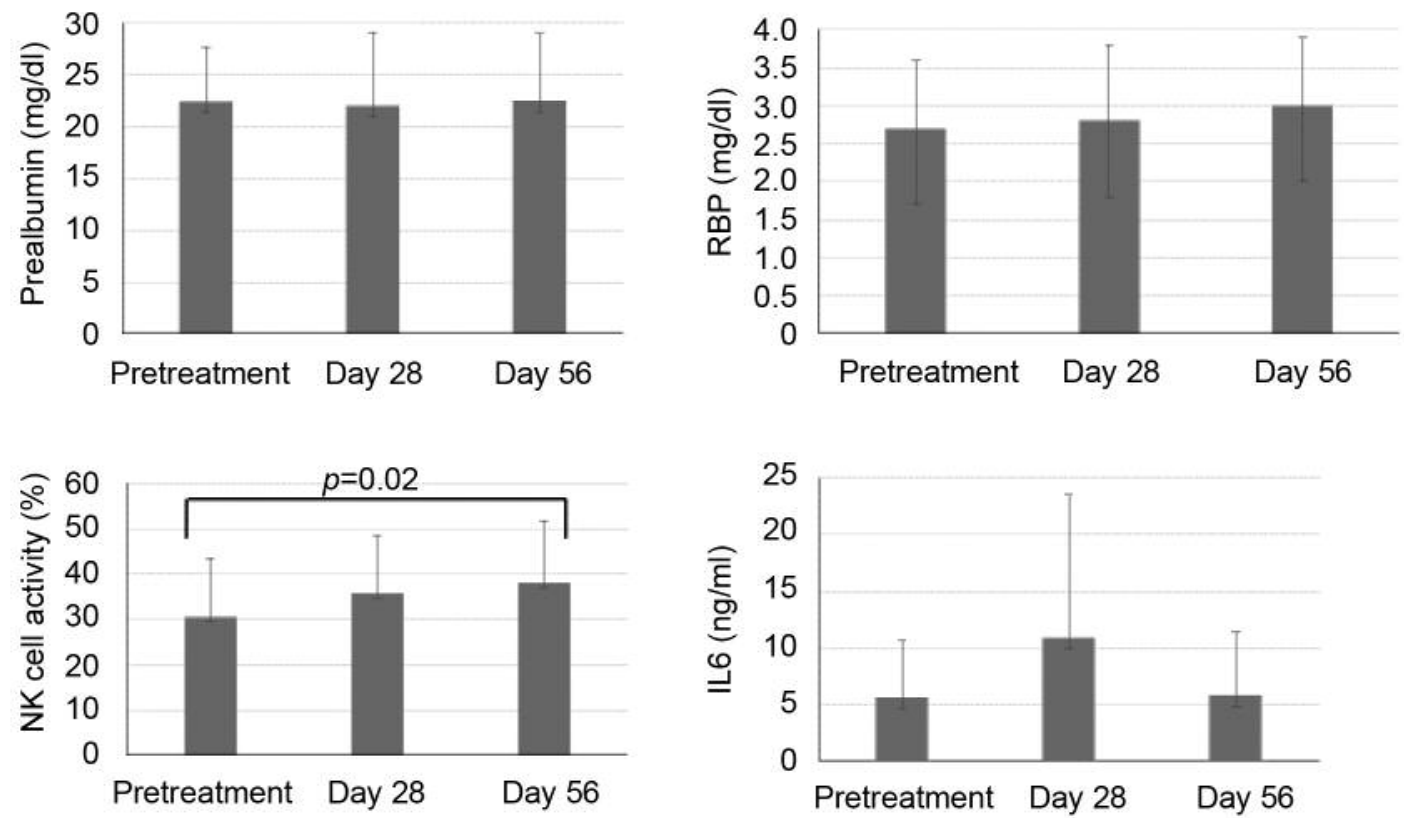

Figure 6. Effects of nutritional support on nutritional and immunological indicators in patients with pancreatic cancer. The analysis of nutritional and immunological blood data in the pancreatic cancer patients revealed a significant increase in natural killer (NK) cell activity from pretreatment to day 56, suggesting an improvement in immune function through treatment. IL6: Interleukin-6; RBP: retinol-binding protein.
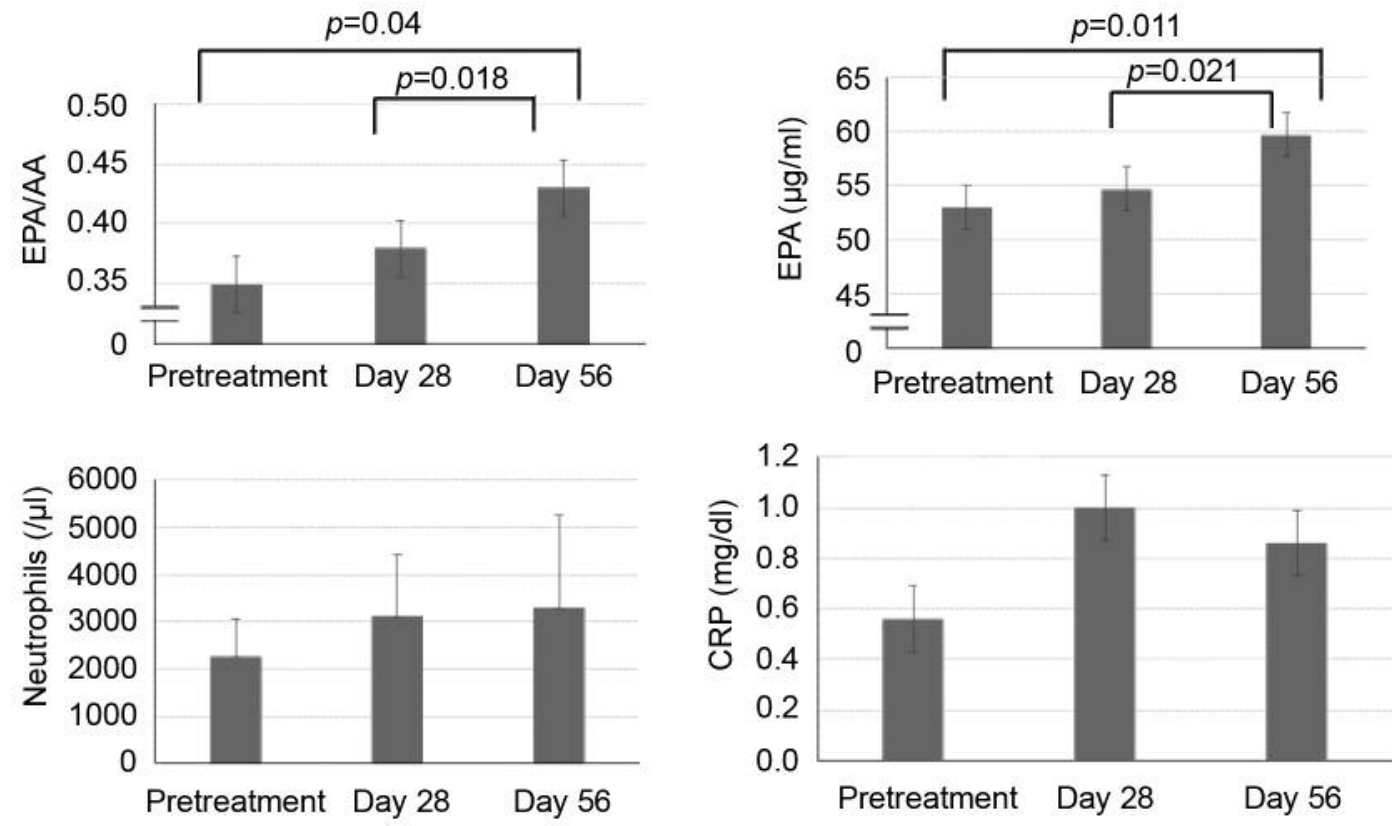

Figure 7. Effects of nutritional support on blood concentrations of eicosapentaenoic acid (EPA) and the levels of neutrophils and C-reactive protein $(C R P)$ in patients with pancreatic cancer. While no significant change was found in the blood concentrations of EPA or EPA/arachidonic acid (AA) on day 28, a significant increase from the pretreatment levels was detected on day 56. The increase from day 28 to day 56 was also significant.

ratios. These findings suggest that the administration of pancreatic digestive enzymes promoted more efficient absorption of omega-3 fatty acids and improved the supplementation effects. Omega-3 fatty acids also increased the NK cell activity at week $8(p=0.02)$, conferring an effect suggestive of activated tumor immunity. 

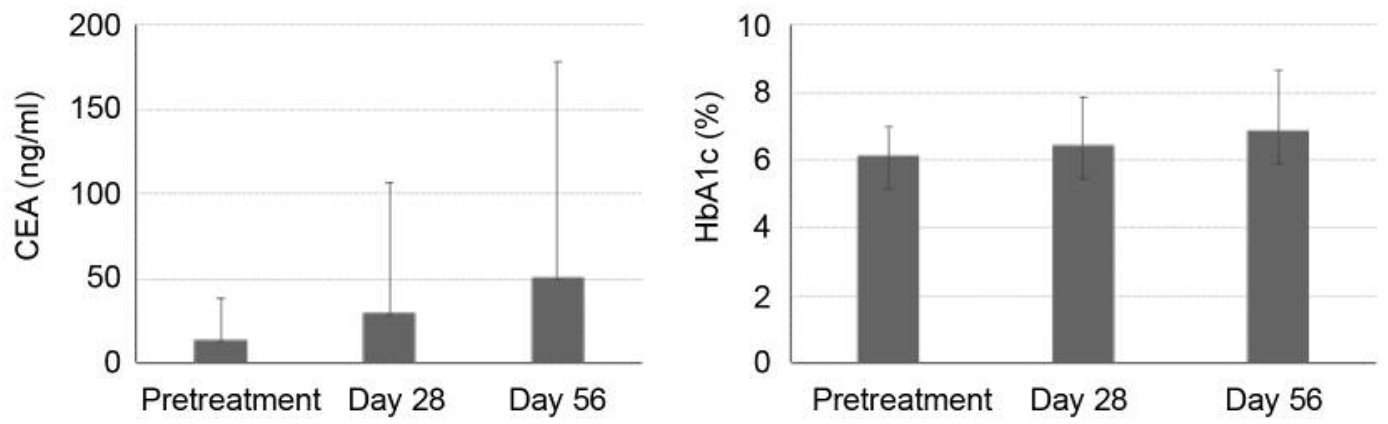

Figure 8. Effects of nutritional support on levels of carcinoembryonic antigen (CEA) and hemoglobin Alc (HbAlc) in patients with pancreatic cancer. There were no significant differences in the results for CEA and HbAlc in the patients with pancreatic cancer.

Examination of all patients and the patients with pancreatic cancer alone showed no effects on immune indicators apart from NK cell activity (i.e. IL-6 and CRP), and no effects on nutritional indices [i.e. pre-albumin and retinol-binding protein (RBP)]. Omega-3 fatty acids reportedly prevented neutropenia in patients with esophageal cancer undergoing preoperative adjuvant chemotherapy (18). Our patients, in contrast, showed no improvement of chemotherapy-associated neutropenia, possibly because they received a different dose of omega- 3 fatty acids. As patients overdosed with omega-3 fatty acids have sometimes developed adverse events such as bleeding or gastrointestinal symptoms (25), our patients received a dose within the range approved by the Japanese Public Health Insurance System. Although not established, the necessary dose of omega-3 fatty acids for the general population is estimated to be at least $2 \mathrm{~g}$ /day $(15,16,26)$, at least double the mean amount $(0.3 \mathrm{~g} /$ pack $\times 2.3$ packs $)$ ingested by our participants. If we had utilized this higher dose, the nutritional support might have further improved the skeletal muscle mass and cancer cachexia in our patients.

Nutritional support with omega-3 fatty acids for biliarypancreatic cancer was safe and increased skeletal muscle mass, especially in patients with pancreatic cancer. Moreover, pancreatic digestive enzyme supplements improved the absorption of omega- 3 fatty acids in patients with pancreatic cancer. The ideal dose of omega-3 fatty acids remains to be elucidated.

\section{Conflicts of Interest}

The Authors declare that they have no conflicts of interest.

\section{References}

1 Rosenberg IH: Fish: food to calm the heart. N Engl J Med 346(15): 1102-1103, 2002.
2 Concetta F, Olivia S, Maurizio F, Taira M, Mara S, Marina S, Marco T, Elisa T, Maria GC, Mariateresa P, Nicoletta F, Manuela A, Giuliana M, Marina M, Manuela O and Rosa AC: Effect of n-3 fatty acids on patients with advanced lung cancer: a doubleblind, placebo-controlled study. Br J Nutr 108: 327-333, 2012.

3 Ross JA, Moses AG and Fearon KC: The anti-catabolic effect of n-3 fatty acids. Curr Opin Clin Nutr Metab Care 2: 219-226, 1999.

4 De Leiris J, De Lorgeril M and Boucher F: Fish oil and heart health. J Cardiovasc Pharmacol 54: 378-384, 2009.

5 Mayer K and Seeger W: Fish oil in critical illness. Curr Opin Clin Nutr Metab Care 11: 121-127, 2008.

6 Singer P and Shapiro H: Enteral omega-3 in acute respiratory distress syndrome. Curr Opin Clin Nutr Metab Care 12: 123128, 2009.

7 Holub BJ: Docosahexaenoic acid (DHA) and cardiovascular disease risk factors. Prostaglandins Leukot Essent Fatty Acids 81: 199-204, 2009.

8 Friesecke S, Lotze C, Kohler J, Heinrich A, Felix SB and Abel P: Fish oil supplementation in the parenteral nutrition of critically ill medical patients: a randomised controlled trials. Intensive Care Med 34: 1411-1420, 2008.

9 Barber MD, Ross JA, Preston T, Shenkin A and Fearon KCH: Fish oil-enriched nutritional supplement attenuates progression of the acute-phase response in weight-losing patients with advanced pancreatic cancer. J Nutr 129(6): 1120-1125, 1999.

10 Fearon KC, von Meyenfeldt MF, Moses AG, Van Geenen R, Roy A, Gouma DJ, Giacosa A, Van Gossum A, Bauer J, Barber MD, Aaronson NK, Voss AC and Tisdale MJ: Effect of a protein and energy dense n-3 fatty acid enriched oral supplement on loss of weight and lean tissue in cancer cachexia: a randomised double blind trial. Gut 52: 1479-1486, 2003.

11 Wigmore SJ, Barber MD, Ross JA, Tisdale MJ and Fearon KC: Effect of oral eicosapentaenoic acid on weight loss in patients with pancreatic cancer. Nutr Cancer 36(2): 177-184, 2000.

12 Tisdale MJ: Metabolic abnormalities in cachexia and anorexia. Nutrition 16: 1013-1014, 2000.

13 Bruera E, Strasser F, Palmer JL, Willey J, Calder K, Amyotte G and Baracos V: Effect of fish oil on appetite and other symptoms in patients with advanced cancer and anorexia/cachexia: a double-blind, placebo-controlled study. J Clin Oncol 21(1): 129134, 2003. 
14 Jatoi A, Rowland K, Loprinzi CL, Sloan JA, Dakhil SR, MacDonald N, Gagnon B, Novotny PJ, Mailliard JA, Bushey TI, Nair S and Christensen B: An eicosapentaenoic acid supplement versus megestrol acetate versus both for patients with cancerassociated wasting: a North Central Cancer Treatment Group and National Cancer Institute of Canada Collaborative Effort. J Clin Oncol 22(12): 2469-2476, 2004.

15 Wigmore SJ, Barber MD, Ross JA, Tisdale MJ and Fearon KC: Effect of oral eicosapentaenoic acid on weight loss in patients with pancreatic cancer. Nutr Cancer 36: 177-184, 2000.

16 Barber MD, Ross JA, Voss AC, Tisdale MJ and Fearon KC: The effect of an oral nutritional supplement enriched with fish oil on weight-loss in patients with pancreatic cancer. Br J Cancer 81(1): 80-86, 1999.

17 van der Meij BS, Schoonbeek CP, Smit EF, Muscaritoli M, van Leeuwen PA, Langius JA. Pre-cachexia and cachexia at diagnosis of stage III non-small-cell lung carcinoma: an exploratory study comparing two consensus-based frameworks. Br J Nutr 109(12): 2231-2239, 2013.

18 Murphy RA, Mourtzakis M, Chu QSC, Baracos VE, Reiman T and Mazurak VC: Nutritional intervention with fish oil provides a benefit over standard of care for weight and skeletal muscle mass in patients with nonsmall cell lung cancer receiving chemotherapy. Cancer 117(8): 1775-1782, 2011.

19 Fearon KCH, Barber MD, Moses AG, Ahmedzai SH, Taylor GS, Tisdale MJ and Murray GD: Double-blind, placebo-controlled, randomized study of eicosapentaenoic acid diester in patients with cancer cachexia. J Clin Oncol 24(21): 3401-3407, 2006.

20 Barber MD, Ross JA, Voss AC, Tisdale MJ and Fearon KCH: The effect of an oral nutritional supplement enriched with fish oil on weight-loss in patients with pancreatic cancer. Br J Cancer 81(1): 80-86, 1999

21 Bauer J, Capra S, Battistutta D, Davidson W and Ash S: Compliance with nutrition prescription improves outcomes in patients with unresectable pancreatic cancer. Clin Nutr 24(6): 998-1004, 2005.
22 de Luis DA, Izaola O, Aller R, Cuellar L and Terroba MC: A randomized clinical trial with oral immunonutrition ( $\omega 3$ enhanced formula $v s$. arginine-enhanced formula) in ambulatory head and neck cancer patients. Ann Nutr Metab 49(2): 95-99, 2005.

23 Miyata H, Yano M, Yasuda T, Yamasaki M, Murakami K, Makino T, Nishiki K, Sugimura K, Motoori M, Shiraishi O, Mori M and Doki Y: Randomized study of the clinical effects of $\omega-3$ fatty acid-containing enteral nutrition support during neoadjuvant chemotherapy on chemotherapy-related toxicity in patients with esophageal cancer. Nutrition 33: 204-210, 2017.

24 Murphy RA, Mourtzakis M, Chu QS, Baracos VE, Reiman T and Mazurak VC: Supplementation with fish oil increases firstline chemotherapy efficacy in patients with advanced nonsmall cell lung cancer. Cancer 117(16): 3774-3780, 2011.

25 Yokoyama M, Origasa H, Matsuzaki M, Matsuzawa Y, Saito Y, Ishikawa Y, Oikawa S, Sasaki J, Hishida H, Itakura H, Kita T, Kitabatake A, Nakaya N, Sakata T, Shimada K and Shirato K: Effects of eicosapentaenoic acid on major coronary events in hypercholesterolaemic patients (JELIS): a randomised openlabel, blinded endpoint analysis. Lancet 369(9567): 1090-1098, 2007.

26 Colomer R, Moreno-Nogueira JM and Garcia-Luna PP, GarcíaPeris P, García-de-Lorenzo A, Zarazaga A, Quecedo L, del Llano J, Usán L and Casimiro C: N-3 fatty acids, cancer and cachexia: a systematic review of the literature. Br J Nutr 97(5): 823-831, 2007.
Received January 11, 2018

Revised February 25, 2018

Accepted February 27, 2018 